\title{
Bacterial infections in the dialysis
}

\section{SEIKHRI-ARAFA。 ${ }^{1} *$ ALILAG。 $\mathbb{H}^{2}$}

1. Faculty of Natural Sciences and life, Department of Microbiology, University of

Constantine1, Algeria. Phone no: 0021355778541

2. Microbial Laboratory, Renal Clinic of Daksi, Constantine, Algeria.

Phone no 00213550496540.

\section{ABSTRACT}

AIMS: Our study focused on bacterial infections in dialysis patients (under peritoneal dialysis or hemodialysis).

Method: this study was carried out for six months, from January to June 2017 at the bacteriology laboratory of the renal clinic of Daksi of Constantine. The analysis was carried out on strains isolated from different pathological samples.

The identification of bacteria was achieved by the conventional methods used in the laboratory, namely the study of their morphological, biochemical API cropping and galleries (analytical index profile). The detection of resistance phenotypes was studied by the conventional method of dissemination of antibiotic disks on medium agar Mueller Hinton and reading and interpretation criteria recommended by the Clinical and Laboratory Standard Institute (CLSI).

Results: 200 cases of infectious were analyzed. Results showed that the majority of patients are treated by peritoneal dialysis with a higher frequency $(63.80 \%)$ than those treated with hemodialysis $(36,19) .112$ bacterial strains were isolated from various samples. Analysis of dialysate samples showed a clear predominance of Gram-positive Cocci (75\%) versus Gramnegative bacilli (25\%). First there are the staphylococci with a frequency of $62,5 \%$ followed Enterobacteriaceae with a predominance of E. coli to $17,85 \%, 12.5 \%$ of Streptococcus, and gram negative bacilli not fermenting with predominance of Pseudomonas aeruginosa, with a percentage of $7,14 \%$.

Conclusion: In this study we have identified the organisms responsible for infections in dialysis patients and their antibiotic resistance. The frequency of these infections is significant. The diagnosis of infections has identified the main germs in question. The isolated bacteria show resistance to several antibiotics tested which aggravates the situation of this immune- suppressed population and diminishes the therapeutic possibilities. The best treatment remains the prevention by the early detection of these infections. Compliance with hygiene measures, individual and collective cleanliness and maintenance of the hospital environment

.Keywords: Infections, Staphylococcus aureus, dialysis patient, dialysis, Antibiotics

Resistance

\section{*Corresponding author: DR Sekhri-Arafa Nedjoua: e-mail: villaouroud@yahoo.fr} Mobile: 0021355778541 


\section{INTRODUCTION}

The number of patients affected by renal insufficiency (RI) is increasing worldwide.

The incidence and prevalence of renal insufficiency have increased significantly over the last few years. According to the World Health Organization (WHO), IR is currently the 12th leading cause of death and the 17th leading cause of morbidity in the world $[1,2]$.

Dialysis is a treatment of modern medicine commonly used for the purpose of temporarily Supplementing failing renal function in order to improve the quality of life of patients [3].

Despite advances in extra renal cleansing techniques, they are responsible for many complications, including infectious complications. These infections are the second leading cause of hospitalization and mortality in dialysis patients [4, 5]. Dialysis patients have a particular susceptibility to infection, nosocomial or community. These infections are frequent in these patients for reasons related to their pathology and supportive therapy, but the frequency of these infections varies from country to country, from hospital to hospital, to patient and health care, and is influenced by various risk factors, in particular hygiene conditions $[7,8]$.

Bacterial infections are an important cause of mortality in patients with chronic hemodialysis. These infections account for $3 / 4$ of the bacterial infections in the world [7, 6]. The most frequent entry point for staphylococcal bacteremia is infection of vascular access $[9,10]$.

\section{MATERIAL AND METHODS}

Our study focused on bacterial infections in dialysis patients (under peritoneal dialysis or hemodialysis) for a period of six months. The patients included are hospitalized in the dialysis department and receive their treatment temporarily in the dialysis unit of the renal clinic of Daksi, Constantine, Algeria.

- 200 pathological samples from inpatients were analyzed. The samples concerned are: collection of peritoneal dialysis fluid (PD), pus, blood culture, and vaginal specimen.

The liquid sample (DP) is made from the patient's bladder pouch. It is carried out using a sterile syringe after stirring the contents of the bag to homogenize the liquid. The liquid is immediately introduced into a sterile tube and deposited directly in the bacteriology laboratory for the isolation and identification of aerobic, facultative and anaerobic aerobic bacteria $[11,12]$.

The vaginal specimen collects vaginal secretions that are taken from the vaginal wall and must be done in the absence of any treatment (antibiotic or antiseptic) with a sterile swab.

The removal of pus makes it possible to isolate the micro-organism responsible for the infection and to identify it. This sampling is done by aspiration using a syringe or by swabbing (in a sterile swab tube).

Blood culture is a method of biological diagnosis which consists in culturing a blood sample to identify the different germs (aerobic and anaerobic).

- The isolation of the bacterial strains is done by culturing the samples on different media Agar: nutrient agar, Chapman agar, cooked blood agar (Chocolate), Hektoën agar, by the method of the stripes using the swab. The dishes are then incubated at $37^{\circ} \mathrm{C}$ for 24 to 48 hours. The culture media used are essential for bacterial multiplication, which allows bacterial identification as well as the study of resistance to antibiotics when the bacterium is isolated in pure culture [13].The identification of bacteria was obtained by the conventional methods used in the laboratory, namely the study of their morphological, biochemical API cropping and galleries and resistance to antibiotics on Muller Hinton media. The demonstration of the generation of $\beta$-lactamases with extended spectrum (ESBL) was achieved by the synergy test between amoxicillin + clavulanic acid and 
cephalosporins $3^{\text {rd }}$ generation $\mathrm{s}$ according to CLSI method. The image of synergy so-called champagne cork is characteristic of the presence of ESBL

\section{RESULTS AND DISCUSSION}

\section{1) General distribution of the population studied}

The results of our study show that of the 200 samples analyzed, the predominance is of the male sex with a percentage of $51.42 \%$ against $48.57 \%$ for the female sex. The sex ration is 1.06 .

Table 1: Distribution of the study population by sex.

$\circ$

\begin{tabular}{|lll|}
\hline Sex & Number & Frequency \% \\
Man & $\mathbf{1 0 4}$ & $\mathbf{5 1 . 4 2 \%}$ \\
Wife & 96 & $48.57 \%$ \\
Total & 200 & $100 \%$ \\
\hline
\end{tabular}

\section{2) Distribution according to the type of dialysis}

Our study shows that of the 200 dialysis patients, the majority of patients are treated by peritoneal dialysis with a higher frequency $(63.80 \%)$ than those treated with hemodialysis $(36,19)$. This is close to what has been reported in a study conducted in Algeria, where $64 \%$ of patients treated with peritoneal dialysis [14]. According to the results, peritoneal dialysis is the treatment of choice for chronic renal failure due to its character of home treatment; Patients prefer not to move 3 times a day to the hospital.

Table 2: Distribution of the study population according to the type of dialysis.

\begin{tabular}{|lcl|}
\hline Type of dialysis & Number & Frequency \% \\
Hemodialysis & 75 & $36.19 \%$ \\
Peritoneal Dialysis & 125 & $\mathbf{6 3 . 8 0 \%}$ \\
Total & 200 & $100 \%$ \\
\hline
\end{tabular}

\section{3) Distribution by culture}

Of the 200 samples analyzed, 112 cases were positive, $53.33 \%$, 88 cases negative, $41.90 \%$, and 10 contaminated cases, representing $4.76 \%$ (the flora was poly-microbial), for which a new levy was necessary.

Table 3: Distribution of the study population according to culture. $N=200$

\begin{tabular}{|l|l|l|}
\hline Culture & Number & Frequency \% \\
\hline Positive & $\mathbf{1 1 2}$ & $\mathbf{5 3 . 3 3}$ \\
\hline Negative & 88 & 41.90 \\
\hline Contaminated & 10 & 4.76 \\
\hline Total & 200 & 100 \\
\hline
\end{tabular}




\section{4) Bacteriological profile of infections of the population investigated}

Distribution of strains by group and species of bacteria

Analysis of dialysate samples during our study period showed a clear predominance of Gram-positive Cocci (75\%) versus Gram-negative bacilli (25\%). First there are the staphylococci with a frequency of $62,5 \%$ followed Enterobacteriaceae with a predominance of $E$. coli to $17,85 \%, 12.5 \%$ of Streptococcus, and gram negative bacilli not fermenting with predominance of Pseudomonas aeruginosa, with a percentage of $7,14 \%$.

The most encountered species among Gram-positive cocci are staphylococci with predominance of S. aureus $37.5 \%$ followed by S. epidermidis (SNA) at $25 \%$.

Our results are in line with those of the literature, which announce that Gram-positive organisms are the most common pathogens encountered in dialysis patients.

The most common causative organism is Staphylococcus aureus (S. aureus) but white staphylococci (Staphylococcus epidermidis) coagulase-negative, are also often found [15]. Predominance of Staphylococcus aureus is explained by the fact that commensal bacterium of the present man in the nasal cavity and the skin makes dialysis patients vulnerable to infections by this organism, with a vascular access which is its major gateway.

The importance of Staphylococcus aureus infections in dialysis is the consequence of the interaction between a pathogen well equipped and a set of local and systemic predisposing factors $[\mathbf{1 6}, \mathbf{1 7}]$.

Staphylococcus aureus is a formidable pathogen that has the ability to colonize about half of the population on dialysis with no signs of disease, but it can cause wound infections and tissue and can also cause septicemia.

So Staphylococcus aureus is the leading cause of morbidity and infectious mortality in dialysis patients [18].

Table 4: Distribution of the strains according to the group and the species of bacteria. $\mathrm{N}=112$

\begin{tabular}{|c|c|c|c|c|c|}
\hline $\begin{array}{l}\text { Group } \\
\text { bacteria }\end{array}$ & of Number & $\begin{array}{l}\text { Frequency } \\
\%\end{array}$ & The bacterial species & Number & Frequency \% \\
\hline \multirow[t]{3}{*}{$\begin{array}{l}\text { Cocci } \\
\text { Gram + }\end{array}$} & 84 & 75 & $\begin{array}{l}\text { Staphylococcus } \\
\text { aureus (SCP) }\end{array}$ & 44 & 37.5 \\
\hline & & & $\begin{array}{l}\text { Staphylococcus } \\
\text { Epidermidis }(\mathrm{SCN})\end{array}$ & 27 & 25 \\
\hline & & & Streptococcus sp & 13 & 12.5 \\
\hline Bacille & 28 & 25 & E.coli & 20 & 17.85 \\
\hline Gram- & & & $\begin{array}{l}\text { Pseudomonas } \\
\text { aeruginosa }\end{array}$ & 8 & 7.14 \\
\hline Total & 112 & 100 & Total & 112 & 100 \\
\hline
\end{tabular}

\section{5) Distribution of strains according to sex}

Of the 112 samples analyzed, 56 strains were isolated from female patients and 56 strains were isolated from male patients, thus equal distribution. This is consistent with those of [19]. According to these results, this physiological criterion does not seem to influence infections in dialysis patients. According to sex, the frequency of isolation is statistically insignificant. 


\section{6) Distribution of strains according to age}

Regarding age, our study shows that most patients affected by infections are between 40-60ans with a percentage of $42.85 \%$, this result is similar to that found by [20] with a percentage of $35.29 \%$ in this age group. This is probably due to the aging population, increased incidence of type 2 diabetes, and poor management of renal replacement patients [21].

Table 5: Stem Age Distribution. (70 is the number of known age patients)

\begin{tabular}{|lll|}
\hline Age & Number of strains & Frequency \% \\
0-20 years & 12 & $17.14 \%$ \\
$\mathbf{2 0 - 4 0}$ years & 14 & $20 \%$ \\
$\mathbf{4 0 - 6 0}$ years & 30 & $\mathbf{4 2 . 8 5 \%}$ \\
$\mathbf{>} \mathbf{6 0}$ years & 14 & $20 \%$ \\
Total & 70 & $100 \%$ \\
\hline
\end{tabular}

\section{7) Distribution of strains according to service}

In our study, the incidence of infections was higher in patients treated with peritoneal dialysis (64.28\%) than those treated with hemodialysis (35.71\%). This result is similar to that reported in the literature indicating that peritoneal infection is the most common complication. The leading cause of discontinuation of the technique, where it is recommended to transfer the patient to hemodialysis $[22,10]$.

Table 6: Distribution of strains according to the service. $\mathrm{N}=112$

\begin{tabular}{|lll|}
\hline Service & Number of strains & Frequency \% \\
\hline Hemodialysis & 40 & $35.71 \%$ \\
\hline Peritoneal Dialysis & 72 & $\mathbf{6 4 . 2 8 \%}$ \\
\hline Total & 112 & $100 \%$ \\
\hline
\end{tabular}

\section{8) Distribution of strains according to the nature of sample}

Overall, analysis of dialysate patient samples during the study period of the 112 strains showed a clear predominance of 28 strains from dialysate ECB with $25 \%$ versus 24 strains of pus (21.42\%), 14 strains for blood culture and hemodialysis catheter with $(12.5 \%)$, 6 strains for vaginal sampling with $(5.35 \%)$, and finally only 4 strains for the ascites fluid with $(3.57 \%)$. These results confirm those reported by literature data; dialysate ECB remains the most recommended sampling in these patients [23, 24].

Table 7: Distribution of strains according to the nature of sample. $\mathrm{N}=112$

\begin{tabular}{|lll|}
\hline Nature of sampling & Number of strains & Frequency \% \\
\hline ECB of Dialysat & $\mathbf{2 8}$ & $\mathbf{2 5 \%}$ \\
Pus & 24 & $21.42 \%$ \\
DP Liquid & 22 & $19.64 \%$ \\
Blood culture & 14 & $12.5 \%$ \\
Hemodialysis Catheter & 14 & $12.5 \%$ \\
Vaginal specimen & 6 & $5.35 \%$ \\
Ascites Liquid & 4 & $3.57 \%$ \\
Total & 112 & $100 \%$ \\
\hline
\end{tabular}




\section{9) Profile of bacterial resistance to different antibiotics}

\section{- Staphylococcus aureus (SCP)}

The resistance of Staphylococcus aureus to penicillin is very high (95\%), our results are consistent with the literature that announces that the secretion of penicillinase is present in 70 to $95 \%$ of $S$. aureus [25].

In dialysis, a study conducted at the University Hospital of Rabat on nasal carriage revealed a resistance of $100 \%$ of $S$. aureus to penicillin [26].

We have 18 cases of resistance to Methiciline (MRSA) or oxacillin (since Methicillin is no longer marketed) among $44 \mathrm{~S}$. aureus strains isolated, a resistance rate of $38.09 \%$. In Algeria, the frequency of MRSA infection was estimated at $14 \%$ in 2001 [27]. Algerian hospitals have thus shown a significant increase of Staphylococcus aureus resistant to methicillin in recent years [28] with a past $10 \%$ in 1997 to around $40 \%$ in 2005. Moreover, according to the 13th evaluation report of Algeria network monitoring, the resistance of bacteria to antibiotics in 2011, the overall analysis of the data concerning the species Staphylococcus aureus results in a percentage of methicillin resistance of $35.37 \%$ of isolates. MRSA rate was $3.44 \%$ in a study conducted in Algeria in peritoneal dialysis patients [29]. In Morocco, the rate of MRSA is 19.3\% [30]. In 2011, the US rate of MRSA was of 4,2\% [31]. In Europe and according to European Antimicrobiol Resistance Surveillance System (EARSS), the MRSA rate rose from 32.95\% in 2002 to $17.1 \%$, the decrease being the result of the fight against cross-transmission.

Our MRSA rate is therefore higher than all of these studies.

In our study, all $S$. aureus strains were sensitive to antibiotics tested with high levels of susceptibility to aminoglycosides.

Among the aminosides, the most active molecules are: $52.38 \%$ Kanamycin, $42.85 \%$ Tobramycin and Gentamycin, and Amikacin 38.09\%.

Concerning the quinolones, our strains are $50 \%$ sensitive to Pipemidic Acid, and with $30 \%$ to Nalidixic Acid.

According to our results, macrolides (Erythromycin), and Lincosamines (Lincomycin,) are effective with the same sensitivity (80.95\%). In contrast, Synergistins (Pristinamycin) are active and are excellent anti-staphylococcal agents (100\%). These results are similar to those of [10] where noted sensitivity rates of $80 \%$ and $100 \%$.

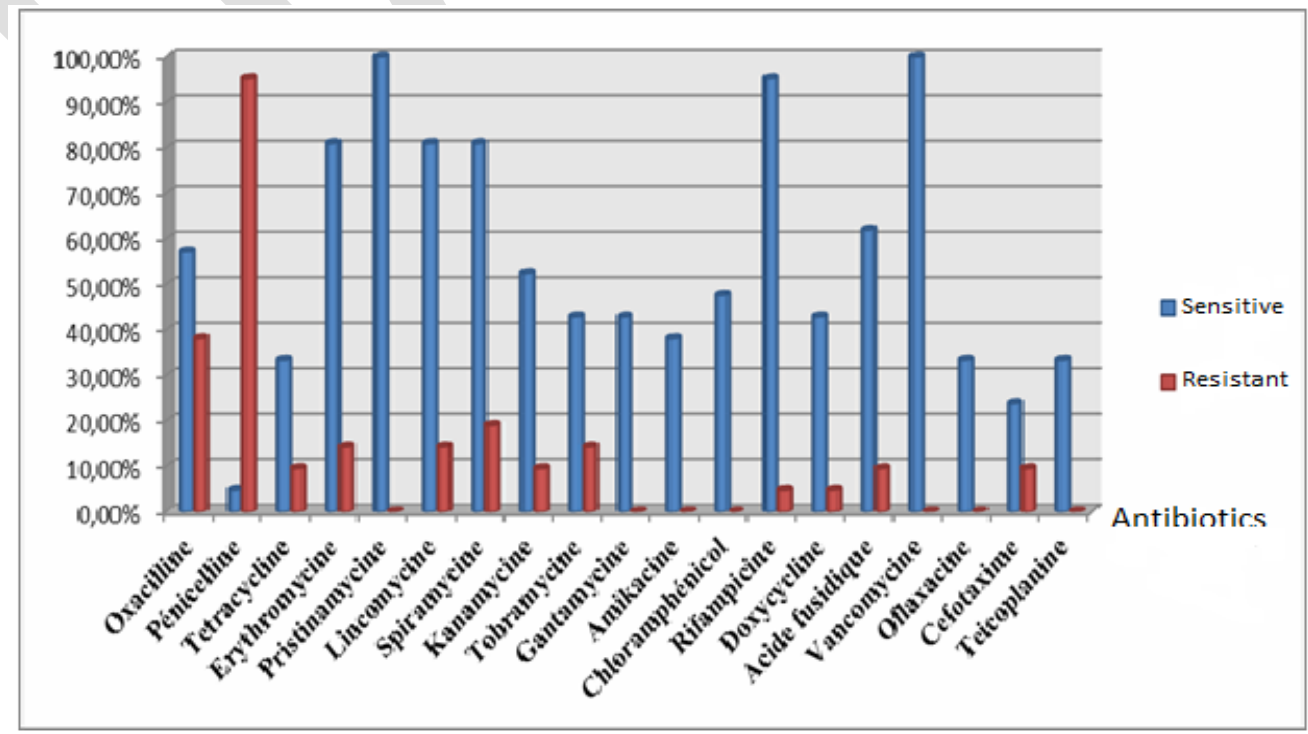

Figure 1: Profile resistance of Staphylococcus aureus to antibiotics. $N=44$ 
Staphylococcus aureus resistance to beta-lactamines involves several mechanisms, either by the plasmid production of beta-lactamases inactivating the antibiotic by opening the beta-lactam ring. Resistant strains develop a PLP 2a (penicillin-binding protein) which is capable of disrupting the assembly of the peptidoglycan and confers resistance to all betalactams [32].

For aminoglycosides, Staphylococcus aureus is sensitive to aminoglycosides but resistances are frequently detected. They may be due to antibiotic inactivation linked to the acquisition of bacterial enzyme genes: ANT (Amin

oside nucleotidyl transferase), APH (Aminoside o-phosphotransferase), or AAC (Aminoside $\mathrm{N}$-acetyltransferase), or by alteration of the ribosome mutation) [32].

The most active molecule is Kanamycin and any strain resistant to this antibiotic is resistant to other Aminosides (KGT phenotype).

As regards quinolones, frequently used resistance mechanisms such as: alteration of the target by a mutation in type II topoisomerases, or by the constitutive efflux systems (over expression of one natural efflux pump mediated by membrane proteins.

\section{- Staphylococcus epidermidis (CNS)}

Staphylococcus epidermidis is the leader of the hulls Gram-positive pathogens, opportunistic and highly implicated in infections in dialysis. In our study, the 27 strains of coagulase negative Staphylococci isolated have multiple resistances to the families of the antibiotics tested.

For $\beta$-lactams, the SCN strains recorded $92.85 \%$ resistance to Penicillin, $64.28 \%$ to Oxacillin, followed by $35.71 \%$ for Cefoxitin. These results are similar to those reported by [33] where all isolated CNS strains were resistant to penicillin. The resistance of the strains to aminoglycosides was variable: $28.57 \%$ for Kanamycin, $21.42 \%$ for Amikacin, and $14.28 \%$ for Gentamycin. There is a fairly marked resistance of $21.42 \%$ for Fluorquinolones (Pefloxacin) and for Tetracycline.

For Macrolides, SCN strains recorded a resistance level of $57.14 \%$ for erythromycin and $28.57 \%$ for Spiramycin and Lincomycin.

For Glycopeptides, they are very active on SCN strains with a sensitivity of $92.85 \%$ to Vancomycin.

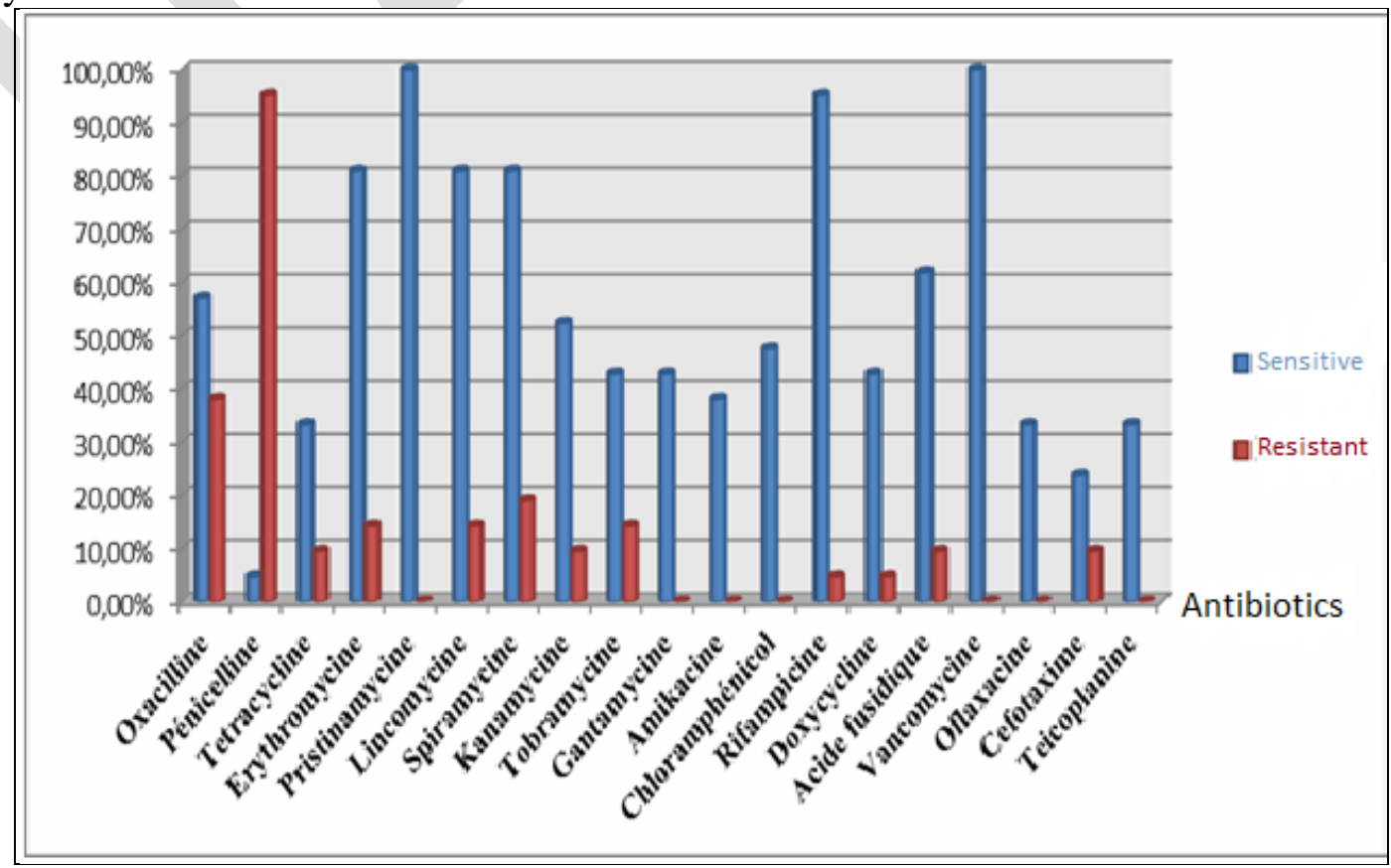

Figure 2: Staphylococcus epidermidis resistance profile Antibiotic $\mathrm{N}=27$. 
Two $\beta$-lactam resistance mechanisms may explain the resistance of Staphylococcus epidermidis. The first is the production of $\beta$-lactamase and the second is the target of change. For the latter mechanism two possibilities: the acquisition of a PLP (penicillin binding proteins) exogenous and / or modification of endogenous PLP [32].

Aminoglycoside resistance in wild phenotype ( $S$. epidermidis) is represented by a primary mechanism such that the enzymatic inactivation, and which can also be explained by the target modification, and membrane permeability [32].

In the case of Fluoroquinolones, a frequently used mechanism such as target alteration (the mutation in I-type topoisomerases), or active efflux, overproduction intrinsic systems and enzymatic inactivation, for example the acquisition of Acetylase [32].

- Streptococci are also part of the bacteria infecting the dialysed patients occupying a more or less important place in pathology. For the resistance of Streptococcus isolated 13 strains in our study, the $\beta$-lactams are the reference antibiotics to treat streptococcal infections [34]. These bacteria register resistance of $42.85 \%$ for Penicillin, followed by a rate of $28.75 \%$ for Oxacillin. For macrolides, strains of Streptococci recorded a resistance rate of $42.85 \%$ to Lincomycin, and $14.28 \%$ to Erythromycins and Spiramycin. There is a fairly marked resistance of $14.28 \%$ for fluoroquinolones (Pefloxacin) and for Tetracycline.

For the Glycopeptides; Streptococcus strains are susceptible to Vancomycin at $85.71 \%$, followed by a $42.85 \%$ rate at Teicoplanin. These results are corroborated by those of the literature [35].

- Regarding antibiotic resistance mechanisms of Streptococcus sp

In our study two mechanisms of $\beta$-lactamines resistance can explain the resistance of streptococci. Target alteration by mutation or recombination of PLP genes and enzymatic inactivation.

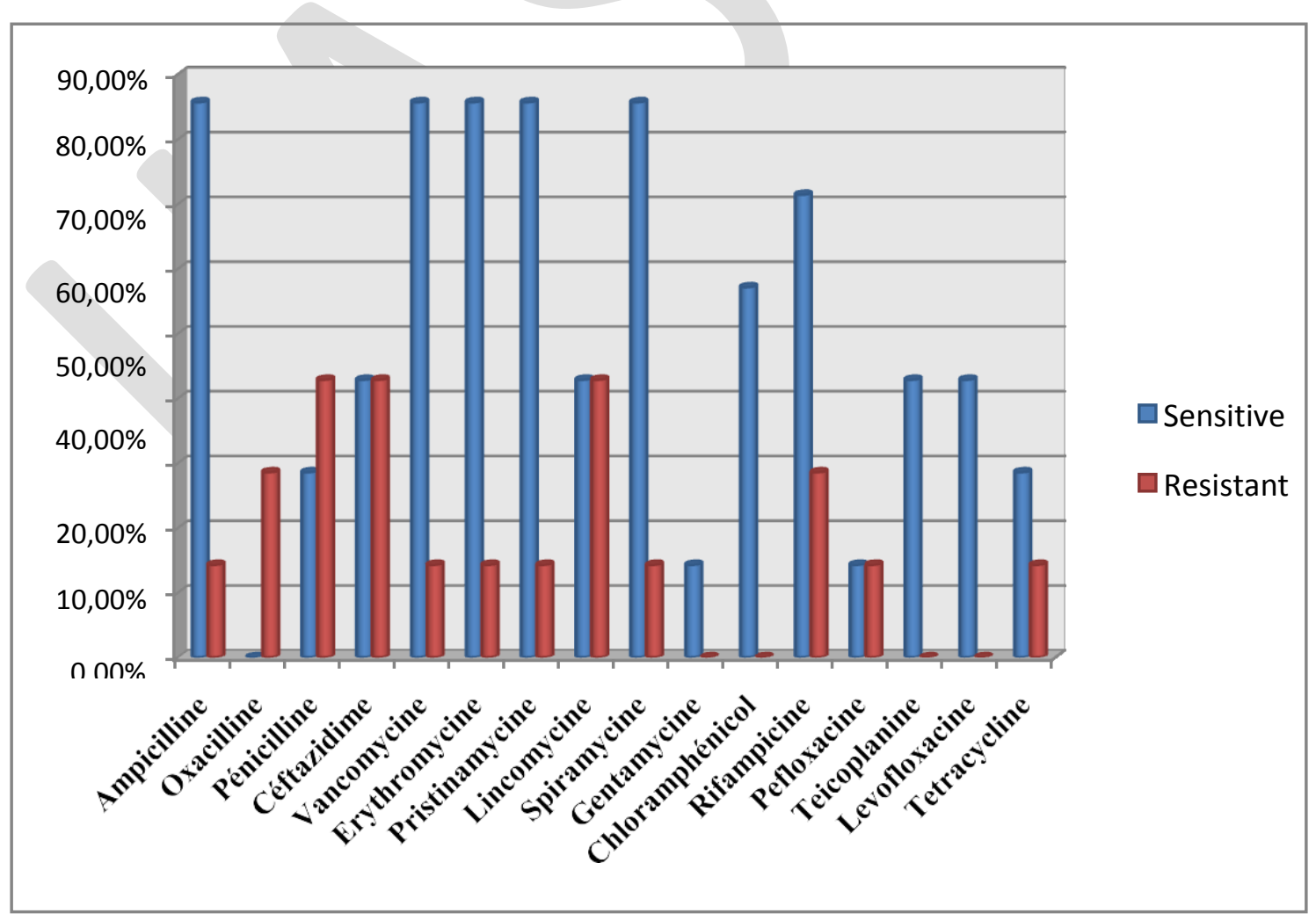

Figure 3: Streptococcus resistance profile $s p$ antibiotic $\mathbf{N}=13$. 
- The strains of E. coli isolated in our study show important resistanc to Amoxicillin and to combination of the amoxicillin+clavulanic acid, with

a rate of $70 \%$, followed by Cefamandole with a resistance rate of $50 \%$. Bactrim resistances are in the fourth position and Pipemidic Acid, which are 30\%, and finally Cefazolin with $20 \%$ resistance,

We have 8 strains resistant to ceftriaxone (E.coli ESBL +) among the 20 strains with a rate of $40 \%$.

On the other hand, these strains show very high susceptibility to Imipenem with $(100 \%)$ for the strains tested, with Ceftriaxone with $(60 \%)$, with Kanamycin, and with Amikacin with $40 \%$.Our results are similar to those reported in the literature: these antibiotics have good activity against strains of $E$. coli.

In our study quinolones retain good activity against E.coli. Nalidixic acid marks a frequency of 30\%, away from that of France with 23.2\% [36], and 50\% to Acid pipemidic.

For fluoroquinolones (ciprofloxacin), our strains are sensitive to a rate of $40 \%$.

In our study; beta-lactams, aminoglycosides, fluoroquinolones, are the antibiotics of choice in the treatment of $E$. coli infections.

\section{- E.coli resistance mechanisms to antibiotics:}

In our study, the high rate of resistance of $E$. coli to $\beta$-lactam antibiotics is due either: the production of $\beta$-lactamases inactivating $\beta$-lactamines (this is the main mechanism of resistance of $E$. coli to $\beta$ - Lactamines), or because of the impermeability of the hydrophilic wall of the Bacteria [37].

For Aminosides, all strains were sensitive to these antibiotics; the total activity was confirmed by [38] $0 \%$ resistance.

In our work, the phenotypes are defined using 4 aminoglycosides: Kanamycin, Tobramycin, Gentamicin, and Amikacin. This allowed us to distinguish a wild phenotype (which has not developed resistance) sensitive to all the aminosides. From a molecular point of view, resistance to Quinolones is commonly acquired through chromosomal mutations or plasmid mutations [32, 39].

\section{Pseudomonas aeruginosa}

Based on our findings, 8 patients were positive for Pseudomonas aeruginosa, which has a high level of natural resistance to antibiotics.

For $\beta$-lactams, Pseudomonas aeruginosa strains recorded a total resistance of $100 \%$ to ceftriaxone and cefotaxime. This result is confirmed by those of [40] where the resistance ratio is $100 \%$, followed by $75 \%$ gentamycin, nalidixic acid, and Clarithromycin, from $50 \%$ to cefoxitin, Kanamycin, and Pipemedic Acid.

Thus, the molecules usually active on these strains are Colistin and Rifampicin with a rate of $100 \%$ sensitivity. Kanamycin and Pefloxacin with a rate of $50 \%$. So these antibiotics are the antibiotics of choice in the treatment of Pseudomonas aeruginosa. Our result is consistent with that reported by $[41,40]$. 


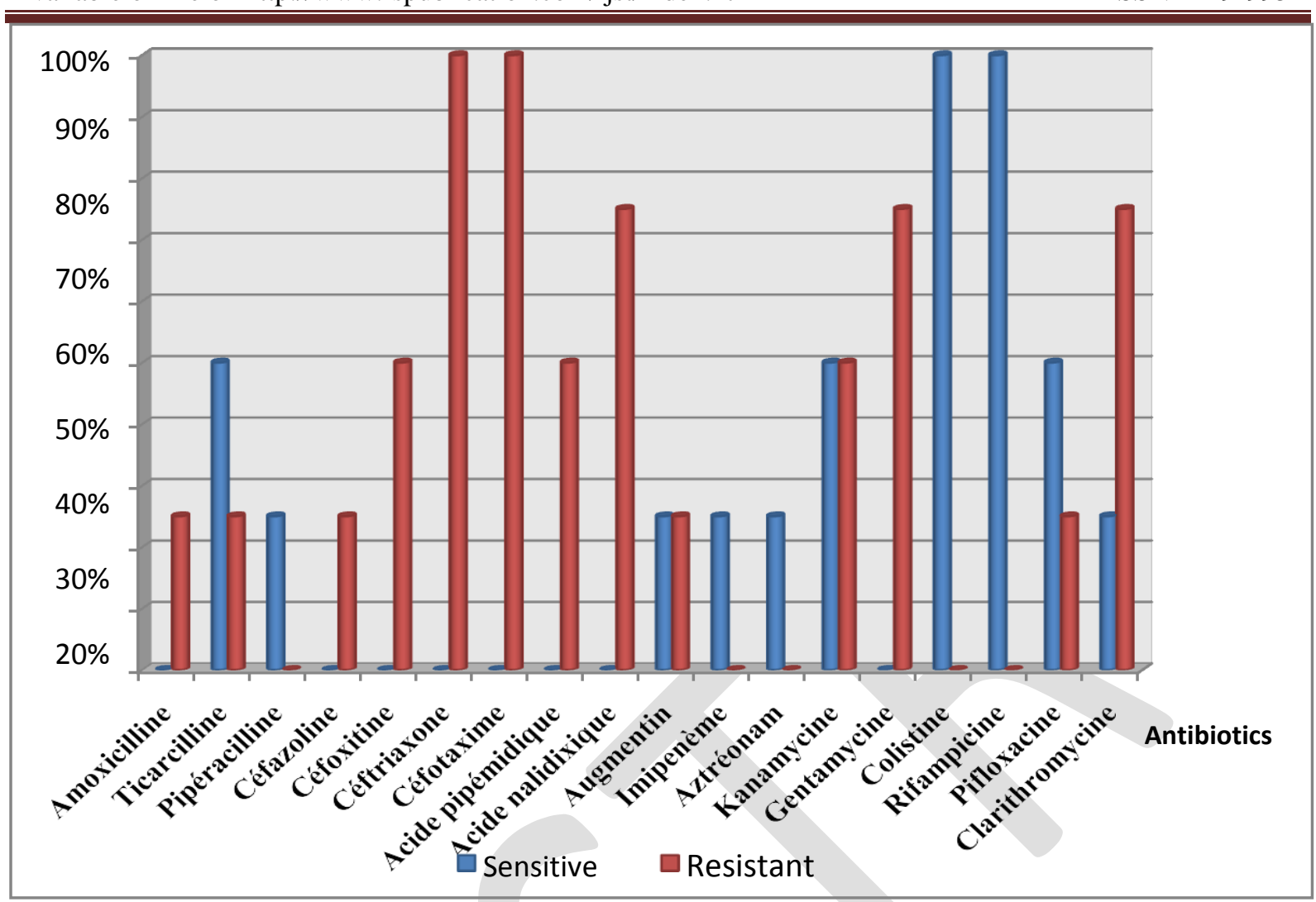

Figure 5: Pseudomonas aeruginosa resistance to antibiotics Profile. $\mathbf{N}=\mathbf{8}$

\section{Resistance mechanisms to antibiotics Pseudomonas aeruginosa:}

In our study, Pseudomonas aeruginosa strains exhibit a very high level of natural resistance to many antibiotics due to either: the poor permeability of the outer membrane, or by the constant production of $\beta$ - lactamase $[32,42]$. The resistances acquired for these antibiotics are very frequent, however, due to the accumulation of different resistance mechanisms linked to chromosomal mutations and the acquisition of transferable genes [43].

For $\beta$-lactams, resistance may be due either to the production of penicillinase inactivating Ticarcillin, or to depressions of the cephalosporinases inactivating all $\beta$-lactams except Imipenem [32].

For aminoglycosides, the strains have a high resistance to

Gentamycin with a level of (75\%), and Kanamycin with a (50\%) level, is mainly due to plasmid modifying enzymes affecting antibiotic binding to 16S RNA, or to transposons encoding for modifying enzymes that generate the resistant phenotypes [44].

For Quinolones, resistance to Nalidixic Acid and Peptic Acid is high (75\%) and (50\%).respectively.

This resistance may be due to the increased impermeability of the outer membrane (selective or non-selective by modification of the porins), or by the active efflux mechanism (association of three membrane proteins that eject the antibiotic)[45].

Conclusion: The infection in dialysis is a major public health challenge because of steady growth in incidence, prevalence, and its medical, social and economic consequences. In our prospective study of bacterial infections in dialysis patients, we have identified the organisms responsible for these infections in this fragile population and their antibiotic resistance. The frequency of these infections in our study is significant; it is $53.33 \%$, with a higher frequency In peritoneal dialysis and in hemodialysis (64.28\% versus $35.71 \%)$. The elderly and immunecompromised are highly exposed to these infections. The samples and infected materials were 
mainly contaminated with gram-positive cocci dominated by the kind of Staphylococci particularly the species Staphylococcus aureus. This bacterial species is the leading cause of infectious mortality in dialysis patients. The isolated bacteria show resistance to several antibiotics tested which aggravates the situation of this immune-suppressed population and diminishes the therapeutic possibilities. Controlling bacterial resistance to antibiotics is a public health priority that requires concerted action in health and research facilities. To control the diffusion of this resistance in these bacteria, it is necessary to use antibiotic therapy, and above all to improve or control the conditions of its use. The best

Treatment remains the prevention by the early detection of these infections. Compliance with hygiene measures, individual and collective cleanliness and maintenance of

The hospital environment (premises, medical equipment) remains the main rules to be taken into consideration.

\section{REFERENCES}

[1]. Levey AS .Definition and classification of chronic kidney disease: a position statement from kidney disease. International Society of Nephrology (2005);Volume 53: p67.

[2]. Florian C. Chronic kidney failure with dialysis, role of the pharmacist dispensary in supporting the dialysis patient. Joseph Fourier University. Faculty of Pharmacy of Grenoble. (2011); p122.

[3]. Society of Nephrology - Dialysis Committee. Patient information: Dialysis. Nephrology and therapeutic . (2006); p 29-31.

[4]. Fontan M, Carmona A, Naveiro R Peritonitis-related mortality in patients Undergoing chronic peritoneal dialysis. . ( 2005); p274.

[5]. Furrer H, Berne, Kiss D, P Francioli, Liestal. . Hemodialysis and nosocomial infection (Part 1). SwissNoso Bulletin | Article ( 2009 ). Swiss.

[6]. Societé Française d'hygiène hospitalière. 2014

[7]. Canaud B., Leray Moragnes H. ( Conduct of hemodialysis and prevention complications. Article archived. EMC (Elsevier Masson SAS, Paris), (2011). Nephrology.

[8].Jungers $\mathbf{P}, \quad \mathbf{K}$ Man Legendre C. Joly D. Chronic kidney disease: prevention andtreatment. $4^{\text {th }}$ edition. Paris : Medical science publication / Lavoisier. ( 2011); p 320.

[9].Hadjlat GH ..Evaluation bacterial water contamination of dialysis machines in Nephrology University Hospital of Tlemcen. Memory Master in Microbiology. University Aoubekr Belkaid. Tlemcen. (2013); p 5-7.

[10]. Harrak S. Epidemiological profile of bacterial infections diagnosed among dialysis CHU Ibn Sina in Rabat. Thesis No. 10.Université Mohammed Souissi. Faculty of Medicine and Pharmacy. Rabat. ( 2014 ); p11, 14, 22, 29, 30, 85,95.

[11]. Archambaud million Clave D.. Direct bacteriological diagnosis of an infection: the samples, the main bacteria involved, interpretation. DCEM 1. Laboratory of BacteriologyHygiene. Faculty of Medicine Toulouse-Rangueil. (2008); p32-33.

[12]. Bourquelot P. Vascular access for hemodialysis. EMC - Nephrology \& Therapeutics. (2009); p 239 - 248.

[13]. Denis F, Ploy M, E Bingen, Quentin R Medical Bacteriology: Technical usuel .2 e edition. Elsevier Masson SAS. Pa laughs. (2011); p30 35.50.

[14]. Boulahia Y. Uremia terminale treated in adults in the wilaya of Algiers in 2004, 2005 and 2006. PhD thesis in medical science. University of Algiers (2009); p18, 30.42.

[15]. Latscha $B$ Jungers $\mathbf{P}$. Immune dysregulation in chronic renal failure. EMC (Encyclopedia Medico-Surgical). Nephrology. La France. (2003); P5-10.

[16]. Vandecasteele S, Boelaert J, Vriese A. Staphylococcus aureus infections in hemodialysis. Clin J Am Soc Nephrol . (2009); p1398-1400. 
[17]. Couve - Deacon E. Portage Staphylococcus aureus in the population of dialysis patients CHU Limoges and Alurad. PhD in medicine. University of Limoges .These No. 3134 (2010); p29.

[18]. Hoen B .. Bacteremic infections with Staphylococcus aureus in hemodialysis patients. 116597YJN -nephro. (2007); p 213.

[19].Dembele S. The hospital infections at the National Hospital point G. Thesis Medicine No. 70. Bamako(2001); p 61.63.

[20]. Boutouha A, Merrouche K.. Urinary tract infection Gram negative bacilli (BGN). Master thesis in general microbiology. 1. University Constantine Algeria. (2013) ; p35.

[21]. Couchaud C, Stengel B, Jacqueline C .Register IRC replacement therapies. Annual Report. Nephrolther (2007); p82.

[22]. Beaudreuil S Hebibi H Charpentier B Durrbachr A. Serious infections in peritoneal dialysis and conventional chronic hemodialysis patients: peritonitis and vascular tract infections.La France. Resuscitation 17. (2008); P233-239.

[23]. Decré D, Gachot B, Lucet JC, Arlet G, Regnier B Monitoring epidemic strains of $E$. coli producing $\beta$-lactamase extended spectrum (E. coli ESBL + ) in an intensive care unit. Rev French laboratories. . (2000); p320

[24]. Ben kaab B, R kheder stripes L.Tuberculose in hemodialysis patients: a 5-year study .Volume 35. Internal Medicine journal. LaFrance. . (2014); p121-123.

[25]. Leclercq R.. Staphylococci antibiotic resistance. Scientific and medical publishing Elsevier SAS. Ann Fr. Anesth Réanim. ( 2002); p375-380.

[26]. El Houssni S, S Loko, Ibrahimi F. Nasal carriage of Staphylococcus peritoneal dialysis. Communications displayed / Nephrology \& Therapeutic. (2012); p296-301.

[27]. Ramdani-Bouguessa N, Bes M, Meugnier H, Forey F, Reverdy ME, Lina G, Vande. Detection of methicillin-resistant Staphylococcus aureus strains resistant to multiple antibiotics and carrying the Panton-Valentine leukocidin genes in an Algiers hospital. Antimicrob Agents Chemother. 2006; 50(3):1083-5.

[28]. Bekkhoucha SN, Cady A, Gautier P, Itim F, Donnio PY A portrait of Staphylococcus aureus from the other side of the Mediterranean sea: molecular characteristics of isolates from Western Algeria. Eur J Clin Microbiol Infect Dis. (2009); 28: 553-555

[29]. Ammari H, Ghaffor M. Bacteriology of peritonitis in patients under continuous ambulatory dialysis (ACSI). Elsevier SAS. Revue Française des laboratoires (2005); p27.

[30]. Elhamzaoui S, Benouda A, Allali F, Abouqual R, Elouennass M. Antibiotic susceptibility of Staphylococcus aureus strains in two university hospitals in Rabat, Morocco.Med Mal Infect; (2009); 39: 891-895.

[31]. Nguyen DB Lessa FC Belflower R. Invasive methicilin-resistant Staphylococcus aureus Infections Among Patients were chronic dialysis in the United States. (2013) ; p397400 .

[32]. Courvalin P, Leclercq R. Antibiogramme. $3^{\text {ème }}$ édition. Eska Edition. La France; (2006); p 117, 125, 133.141, 205, 227, 247, 263.

[33]. Zerari $\mathbf{Z}$ Dje kouadio K. Nosocomial infections: case of urinary tract infection. Master Thesis in Microbiology. Constantine University 1.(2014); p 49, 57.

[34]. Amorose A, D Demares, Mollerach M, Gutkid G, J Coyette. All detectableshighmolecular-mass penicillin-binding proteins are modified in a high-level beta-lactamine resistant clinical isolate of streptococcus. (2001); p81.

[35]. Schmitz F, Fischer A, Boos M, S Mayer, Milatovic D Fluit A. Quinolone-resistance Mechanisms and in vitro susceptibility patterns Among European isolates of Streptococcus. Eur J Clin Microbiol Infect Dis. (2001); p219. 
[36]. Sirot J, Nicolas-Chanoine M, H Chardon, Avril J. 12Susceptibility of Enterobacteriaceae to fluoroquinolones $\beta$-lactam agents: a 3yearSurvey in France. J Clin Microbiol Infect. ( 2002); p 207-210.

[37]. Larabi K., A. Masmoudi, Fendri C. Bacteriological and phenotypic study germs resistance responsible for urinary tract infections in University Hospital of Tunis about 1930cas. Med Mal Infect. (2002); p33.

[38]. Ahriz M and Sid B. . Post-operative infections in Caesarean women in the obstetric gynecology department, Constantine University Hospital. Master's thesis in General Microbiology. University of Constantine. (2014); P13-16, 54.

[39]. Loukiadis E. Virulence factor and release into the environment via effluents from slaughterhouses slaughter animals of Escherichia coli entérohémoragique (EHEC). Thesis University of Toulouse. La France. (2007); p 57.

[40]. Bouarroudj Y, Boutebza FZ. Urinary tract infections. Master's thesis in Microbial Ecology .University of Mentouri Constantine. (2015) ; p56.

[41]. Chaker H. The adaptation control of the bacterium Pseudomonas aeruginosa has its host: involvement of tryptophan metabolites. (2012); p22, 23.

[42]. Bagge N, O Ciofu, Hentzer M. Expression of high .Constitutive chromosomal betalactamase in Pseudomonas aeruginosa caused by a new insertion sequence (IS1669) Located in amp D. Antimicrob Agents Chemother (2002); p11, 46.

[43]. ClaveD . . Bacteriological Datasheet Pseudomonas aeruginosa. Toulouse Center for the Biology quality control clinic (2011).

[44]. Lambert T A Aminoglycosides and Gram negative bacteria. Antibiotic susceptibility. Courvalin P. $2^{\text {nd }}$ edition (2007);226-232.

[45]. Robicsek A, Jacoby GA, Hooper DC. The worldwide emergence of quinolone resistance Plasmidme diated. Lancing, Infect Dis (2006); 6. p40. 